\title{
Development of National Disability Surveillance System in Sri Lanka
}

\author{
Inoka E. Weerasinghe ${ }^{\star 1,2}$ and Sumedha Jayatilake ${ }^{3}$ \\ ${ }^{1}$ Ministry of Health, Colombo, Sri Lanka; ${ }^{2}$ Center for Injury Research and policy, Johns Hopkins University, Baltimore, MD, USA; \\ ${ }^{3}$ Faculty of Dentistry, University of Peradeniya, Peradeniya, Sri Lanka
}

\section{Objective}

To review the national disability statistics and to develop a methodology for the establishment of a national disability surveillance system in Sri Lanka.

\section{Introduction}

A major drawback in disability prevention and rehabilitation in Sri Lanka is the lack of complete, accurate and timely data. National disability surveys conducted as a part of the decennial census lack complete and scientifically accurate information. Further, Sri Lanka has no established disability surveillance system. This review was conducted to explore the national disability data and to develop a methodology for the establishment of a disability surveillance system in Sri Lanka.

\section{Methods}

Medline and Google data bases were searched for published data from 1984 to 2014 using the key words; disability, national disability data, national surveys, national/international disability surveillance and Sri Lanka. Further, disability statistics were reviewed using publications available in Census Department, Central Bank, Postgraduate Institute of Medicine and other governmental and nongovernmental organizations and institutes of Sri Lanka. In addition, both local and international experts in the field of disability, health care surveillance and bio-informatics were interviewed.

\section{Results}

According to the initial survey on disability in Sri Lanka-2001 conducted by the Census and Statistics Department, prevalence of disability was $1.6 \%{ }^{1}$. The Central Bank of Sri Lanka in 1996/97 and 2003/04 conducting Consumer Finance and Socioeconomic Surveys has reported that the prevalence of disability in Sri Lanka was $2.3 \%{ }^{2}$. A survey by the United Nations revealed that the total disability prevalence in Sri Lanka was $2 \%$ in $1986^{3}$. The highest disability prevalence for Sri Lanka was reported by the World Health Survey, 2002-2004 which was $12.9 \%{ }^{4}$.

All above surveys have categorized disability basically according to gross anatomical defects or functional disability and none of them had measured disability using an internationally comparable standard. Limited number of studies has been conducted on specific types of disabilities confined to local areas. However, only a few has used a standard disability measurement such as International classification of Functioning, Disability and Health (ICF) ${ }^{5}$. Standard measurements in the national disability data collection helps to compare the data locally and internationally.

Therefore, following initial steps were identified as key points in the establishment of a national disability surveillance system in Sri Lanka. They are planning ICF based disability surveillance system, piloting the disability surveillance system, testing the possibility of coding and feasibility at selected test sites. Formulation of a commonly agreed ICF based information sheet to report functioning and disability data to an identified central body, setting up of a locally based ICF training for the primary health care workers and curative and rehabilitation care workers, information collection to be done by the primary health administrative areas (Medical Officer of Health areas) which collect the community field data and from the hospital and rehabilitation centers and to send the information to the central body, method of sending information either via post or e-mail, working out an analytical methodology to utilize the information produced and later on to develop a software to report and analyze the data.

\section{Conclusions}

Sri Lankan disability data differ from one data source to the other. Current disability data in Sri Lanka are non-comparable locally and internationally because they are not based on a scientific disability classification system. This highlights the great need of a national disability surveillance system using scientific methods such as ICF.

\section{Keywords}

Disability surveillance; Sri Lanka; Public Health

\section{Acknowledgments}

Authors would like to acknowledge all the experts supported.

\section{References}

1. Brief analysis of the characteristics of the disabled persons, Sri Lanka, Department of Census and Statistics, 2009.

2. Consumer Finances and Socioeconomic survey report 2003/04 Part 1, Central Bank of Sri Lanka, Colombo. Central Bank of Sri Lanka, 2005.

3. United Nations Disability Statistics Database, United Nations, 2011, New York.

4. World Health Survey, Geneva, World Health Organization, 2002-2004

5. International Classification of Functioning, Disability and Health, Geneva, World Health Organization, 2001.

*Inoka E. Weerasinghe

E-mail: eranganie@yahoo.com 